Article

\title{
From High-Manganese Steels to Advanced High-Entropy Alloys
}

\author{
Christian Haase ${ }^{1, *(\mathbb{D})}$ and Luis Antonio Barrales-Mora ${ }^{2}$ D \\ 1 Steel Institute, RWTH Aachen University, Intzestraße 1, 52072 Aachen, Germany \\ 2 George W. Woodruff School of Mechanical Engineering, Georgia Institute of Technology, 2 Rue Marconi, \\ 57070 Metz, France \\ * Correspondence: christian.haase@iehk.rwth-aachen.de; Tel.: +49-241-80-95821
}

Received: 7 June 2019; Accepted: 25 June 2019; Published: 27 June 2019

\begin{abstract}
Arguably, steels are the most important structural material, even to this day. Numerous design concepts have been developed to create and/or tailor new steels suited to the most varied applications. High-manganese steels (HMnS) stand out for their excellent mechanical properties and their capacity to make use of a variety of physical mechanisms to tailor their microstructure, and thus their properties. With this in mind, in this contribution, we explore the possibility of extending the alloy design concepts that haven been used successfully in HMnS to the recently introduced high-entropy alloys (HEA). To this aim, one HMnS steel and the classical HEA Cantor alloy were subjected to cold rolling and heat treatment. The evolution of the microstructure and texture during the processing of the alloys and the resulting properties were characterized and studied. Based on these results, the physical mechanisms active in the investigated HMnS and HEA were identified and discussed. The results evidenced a substantial transferability of the design concepts and more importantly, they hint at a larger potential for microstructure and property tailoring in the HEA.
\end{abstract}

Keywords: high-manganese steels; high-entropy alloys; alloy design; plastic deformation; annealing; microstructure; texture; mechanical properties

\section{Introduction}

One of the most important objectives of materials scientists is the improvement of the mechanical properties of materials. For this purpose, it is possible to make use of diverse physical phenomena that essentially modify the microstructure to either facilitate or complicate the motion and generation of dislocations depending on the requirements of the final component. In the same way as alloys aim to be more than the sum of their parts, modern strengthening concepts aim to combine and-perhaps more important-trigger strengthening mechanisms at the right times. This is the idea behind the high-manganese steels (HMnS), whose mechanical properties are improved by activating either martensitic transformations (transformation-induced plasticity, TRIP) or mechanical twinning (twinning-induced plasticity, TWIP) to achieve higher strength and larger elongation [1]. The combination of these mechanisms with strong planar dislocation glide makes these materials possess outstanding strain-hardening potential attributable to an observed dynamic Hall-Petch effect [2].

Another recently developed class of alloys are the so-called high-entropy alloys (HEA). HEAs are alloys with more than four elements in usually equiatomic or near-equiatomic compositions. The idea behind these alloys is that their high entropy stabilizes the solid solution against the formation of intermetallic phases. HEAs are less well studied than HMnS, but since their discovery by Cantor et al. [3] and Yeh et al. [4], HEAs have attracted much fascination within the research community due to the vast space of possible alloys and thus, potential microstructures and property combinations. Although 
several core effects (high-entropy effect, sever lattice distortion effect, sluggish diffusion effect, cocktail effect) of HEAs have been proposed [5], a clear design strategy is still missing.

The underlying physical mechanisms active in HMnS have already been studied for several decades $[1,2,6]$, and therefore are comparatively well understood. One of the most important parameters when designing HMnS is the tailoring of their stacking fault energy (SFE). This property controls the dissociation distance of partial dislocations and determines whether TRIP and/or TWIP is activated/suppressed during plastic deformation. The role of the SFE during plastic deformation and subsequent heat treatment in metals has been studied for decades, and its effect is relatively well-known for face-centered cubic (fcc) metals [7]. In fcc HEAs, the mechanisms of microstructure formation have been found to occur in a similar way to the same class of alloys with comparable SFE [8]. For instance, the Cantor alloy (CoCrFeMnNi) with an estimated SFE between $18.3-27.3 \mathrm{~mJ} / \mathrm{m}^{2}[9,10]$ has been shown to develop the TWIP effect, depending on the processing conditions [11]. Evidently, the determination of the SFE in HEAs is fundamental, because this property indicates the possible acting mechanisms for microstructure development. However, as with steels, the complex chemistry of HEAs leads to almost unlimited combinations that make a systematic determination of this property difficult. Nevertheless, to accelerate the development of these alloys, several research groups have made use of ab initio calculations, e.g., [12]. The advantage of this method is that it is possible to calculate several alloy compositions with less effort than the one required for an experimental determination of the same alloys. So far, the systems CoCrFeMnNi [9,10,13,14], AlCoCrCuFeNi, and AlCoCrFeNi [15] have been investigated regarding their SFE. A comprehensive list can be found in Reference [12]. First-principle methods have even allowed the constructions of property maps, where the SFE can be read as a function of the chemical composition [14], which can be used to predict the expected physical acting mechanisms. The experimental determination of the SFE, although it is arguably more laborious, is as important as its computational calculation because, as accurate as they are, ab initio calculations still rely on a model, which may not be accurate for some conditions. Thus, experimentation provides the necessary validation of the models. For the experimental determination of the SFE, two methods have been used before: namely, the measurement of the dissociation width of partial dislocations [16] and a combination of X-ray diffraction analysis and first-principle calculations of elastic constants [9]. The strategy of obtaining similar microstructures as those in advanced steels has been successfully utilized in some HEAs. For instance, dual-phase fcc-hcp (hexagonal closest packed) HEAs have substantiated increased ductility and strength [17], owing to the activation of the TWIP and TRIP effects [18]. With this in mind, in the present contribution, the mechanisms active during deformation and annealing in low-SFE single-phase HMnS and HEAs will be compared and discussed in order to put forward an SFE-oriented design of fcc-based HEAs.

\section{Materials and Methods}

Two alloys were investigated: one HMnS and one HEA. The chemical composition and their SFEs are shown in Table 1. The chemical compositions were determined by inductively coupled plasma-optical emission spectrometry (ICP-OES) and combustion analysis. The SFE values of the HMnS were calculated using a subregular thermodynamic solution model [19], whereas the SFE of the HEA was taken from the literature $[9,10]$.

Table 1. Chemical composition (in wt\%) and stacking fault energy (SFE) values of the investigated alloys. The weight fractions of $\mathrm{Al}, \mathrm{Si}, \mathrm{N}$, and $\mathrm{P}$ were not measured in the high-entropy alloys (HEA).

\begin{tabular}{cccccccccccc}
\hline Alloy & Fe & Mn & Al & Co & Cr & Ni & Si & C & N & P & SFE (mJ/m $\mathbf{m}^{2}$ \\
\hline HMnS & Bal. & 22.46 & 1.21 & - & - & - & 0.04 & 0.325 & 0.0150 & 0.01 & 25 \\
HEA & 20.3 & 18.8 & - & 21.8 & 17.9 & 21.0 & - & 0.038 & - & - & $18-27$ \\
\hline
\end{tabular}

Both alloys were melted in an air conduction furnace followed by ingot casting, and were subsequently homogenized at $1150{ }^{\circ} \mathrm{C}$ for $5 \mathrm{~h}$ under protective Ar atmosphere. Then, the ingots were 
forged and subsequently homogenized at $1150^{\circ} \mathrm{C}$. After hot rolling, the alloys were cold rolled at room temperature to achieve up to $50 \%$ thickness reduction. To investigate the influence of additional heat treatment on the material behavior, the HMnS was subjected to annealing treatments at $550{ }^{\circ} \mathrm{C}$ for different times. In turn, the HEA was produced using induction melting in Ar atmosphere followed by hot rolling at $1000{ }^{\circ} \mathrm{C}$ and homogenization at $1000{ }^{\circ} \mathrm{C}$ for $1 \mathrm{~h}$. The hot-rolled sheet was further cold rolled up to $50 \%$ thickness reduction. Finally, the cold-rolled sheets were annealed in the range between $500-900{ }^{\circ} \mathrm{C}$ for $1 \mathrm{~h}$ in an air furnace. The specific parameters used for processing the HMnS and HEA in different conditions are given in Table A1.

For characterization of the HMnS and HEA, specimens with the dimensions $12 \mathrm{~mm} \times 10 \mathrm{~mm}$ in the rolling direction (RD) and transverse direction (TD) were fabricated using electrical discharge machining. The samples were mechanically ground up to $4000 \mathrm{SiC}$ grit paper followed by mechanical polishing using diamond suspensions of $3 \mu \mathrm{m}$ and $1 \mu \mathrm{m}$. For X-ray diffraction (XRD) pole figure measurements, the middle layer of the RD-TD section was polished electrolytically at room temperature for $2 \mathrm{~min}$ at $22 \mathrm{~V}$, whereas the RD-ND (ND-normal direction) section was electropolished for scanning electron backscatter diffraction (EBSD) using the same parameters as before. The electrolyte used for XRD and EBSD sample preparation consisted of $700 \mathrm{~mL}$ of ethanol $\left(\mathrm{C}_{2} \mathrm{H}_{5} \mathrm{OH}\right), 100 \mathrm{~mL}$ of butyl glycol $\left(\mathrm{C}_{6} \mathrm{H}_{14} \mathrm{O}_{2}\right)$, and $78 \mathrm{~mL}$ of perchloric acid $(60 \%)\left(\mathrm{ClO}_{4}\right)$. Transmission electron microscopy (TEM) samples ( $100 \mu \mathrm{m}$ thick, $3 \mathrm{~mm}$ in diameter) were prepared using the same electrolyte as for XRD and EBSD samples in a double jet Tenupol-5 electrolytic polisher with a voltage of 22-29 V and a flow rate of 10 at $15^{\circ} \mathrm{C}(\mathrm{HMnS})$ and $4-6^{\circ} \mathrm{C}$ (HEA).

EBSD analyses were performed in an LEO 1530 field emission gun scanning electron microscope (FEG-SEM) (Carl Zeiss AG, Oberkochen, Germany) operated at 20-kV accelerating voltage and a working distance of $10 \mathrm{~mm}$. The HKL Channel 5 software and the MATLAB ${ }^{\circledR}$-based toolbox MTEX [20-22] were utilized to post-process and visualize the ESBD data. The subdivision of EBSD mappings into subsets containing only non-recrystallized (non-RX) or recrystallized (RX) grains was realized, as described in [23]. TEM analyses were performed in a FEI Tecnai F20 TEM (FEI Company, Hillsboro, OR, USA) operated at $200 \mathrm{kV}$.

X-ray pole figures were acquired utilizing a Bruker D8 Advance diffractometer (Bruker Corporation, Billerica, MA, USA), equipped with a HI-STAR area detector, operating at $30 \mathrm{kV}$ and $25 \mathrm{~mA}$, using filtered iron radiation and polycapillary focusing optics. In order to characterize the crystallographic texture, three incomplete $\left(0-85^{\circ}\right)$ pole figures $\{111\},\{200\}$, and $\{220\}$ were measured. The macrotexture orientation distribution functions (ODFs) were also calculated and visualized using MTEX. The volume fractions of the corresponding texture components were calculated using a spread of $15^{\circ}$ from their ideal orientation.

Mechanical properties were evaluated by uniaxial tensile tests at room temperature and a constant strain rate of $2.5 \times 10^{-3} \mathrm{~s}^{-1}$ along the previous rolling direction on a screw-driven Zwick Z100 mechanical testing device (Zwick/Roell, Ulm, Germany). Flat bar tension specimens were used with a gauge length of $13 \mathrm{~mm}$, gauge width of $2 \mathrm{~mm}$, fillet radius of $1 \mathrm{~mm}$, and a total length of $33 \mathrm{~mm}$.

\section{Results and Discussion}

\subsection{Behavior during Plastic Deformation}

An excellent tool for identifying the mechanisms acting during plastic deformation is the analysis of the crystallographic texture. To exemplify, Figure 1 shows the development of the texture of the HMnS and HEA during cold rolling with thickness reductions from $10 \%$ to $50 \%$. Both alloys evinced the evolution of the main rolling texture components of fcc alloys, namely the $\mathrm{Cu}$, S, Goss, and Brass texture components, whereas the Cube component disappeared. The position and definition of the ideal texture components is given in Figure A1 and Table A2 in Appendix A. With increasing deformation, the orientations tended to cluster at positions between the Brass and Goss texture components. This effect intensified at larger strains. In addition, the Goss component spread toward the CuT texture 
component. Nevertheless, one major difference between the texture of the HMnS and HEA after 50\% cold rolling can be recognized. The $\alpha$-fiber texture components, Brass and Goss, were stronger than the $\mathrm{Cu}$ one in the HMnS, whereas, in the HEA, the Brass component was less pronounced, while the $\mathrm{Cu}$ component was stronger (Figure 1). Therefore, after 50\% cold rolling, the HMnS had already developed a Brass-type texture, while the HEA was characterized by a mixture of Brass-type and Cu-type textures.
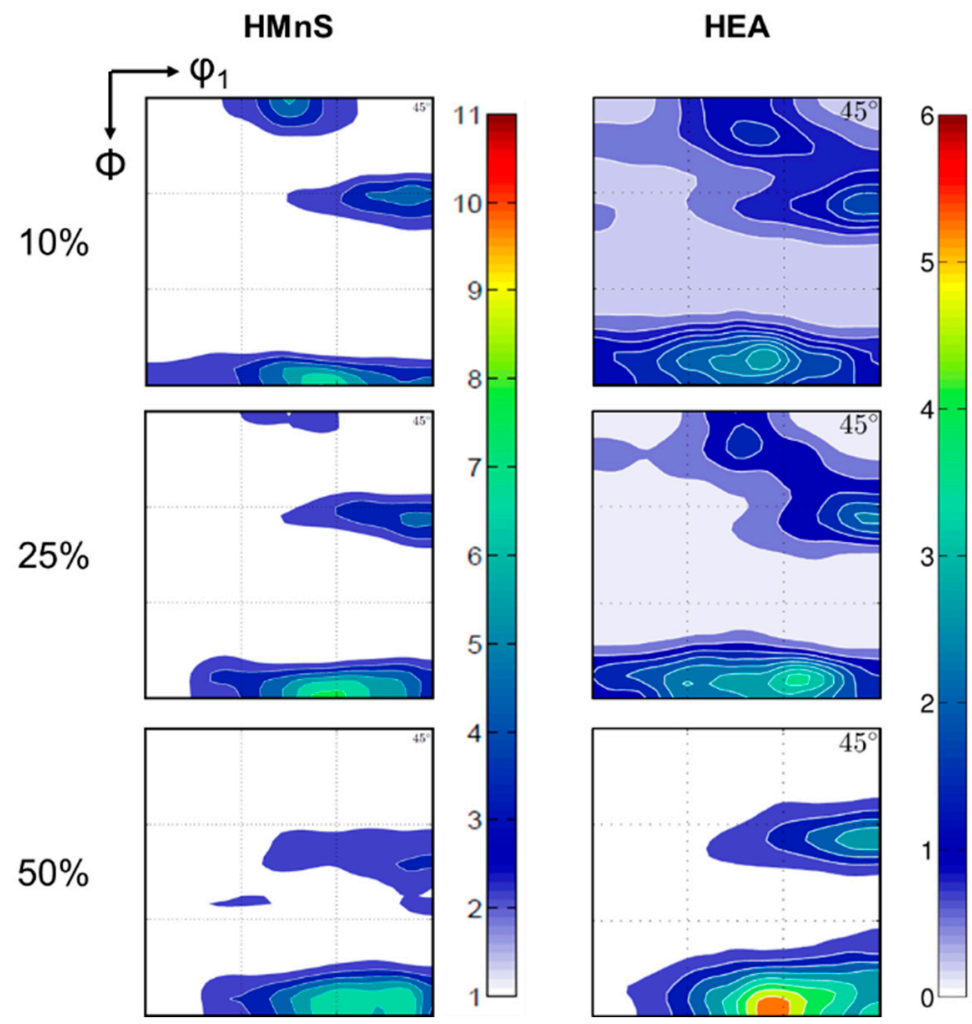

Figure 1. Texture evolution during cold rolling at room temperature of the investigated high-manganese steels (HMnS) and high-entropy alloy (HEA) illustrated by $\varphi_{2}=45^{\circ}$ section of the ODF.

As shown in Figure 2, the microstructure of both alloys after $50 \%$ cold rolling consisted of grains elongated in RD and contained longitudinal features, such as slip bands. Deformation twins and microshear bands developed equally. Nevertheless, it has been proven that at low rolling degrees, deformation twinning in HEAs is less pronounced, and thus contributes to plastic deformation to a lesser extent, as compared to HMnS [8,24]. At high rolling degrees (80-90\%), pronounced Brass-type textures have been observed in HMnS and HEAs [24,25]. Therefore, it can be concluded that the transition from Cu-type to Brass-type texture evolves in low-SFE HEAs in a comparable manner as to that in low-SFE HMnS, but it is shifted to higher degrees of plastic deformation. In terms of the activation of deformation twinning, the presence of $\mathrm{C}$ in the $\mathrm{HMnS}$, and correspondingly the absence of $\mathrm{C}$ in the HEA, is presumably the main influential factor. On the one hand, $\mathrm{C}$ causes an increase of the flow stress, and therefore facilitates achieving the critical resolved shear stress for the activation of twinning. On the other hand, C-Mn short range ordered clusters contribute to the splitting of partial dislocations and ease the onset of deformation twinning [26]. In turn, in the C-free HEA, a more prolonged stage of deformation by dislocation slip retards the initiation of deformation twinning and delays the formation sequence of twin-matrix lamellae, their rotation into the rolling plane, and the subsequent onset of shear banding [27-33], which are thus shifted to higher strains. Hence, the related formation of a pronounced Brass-type texture with the typical texture components-Brass, Goss, CuT and $\gamma$-fiber-is shifted to higher degrees of thickness reduction during rolling of the HEA. 


\section{HMnS}

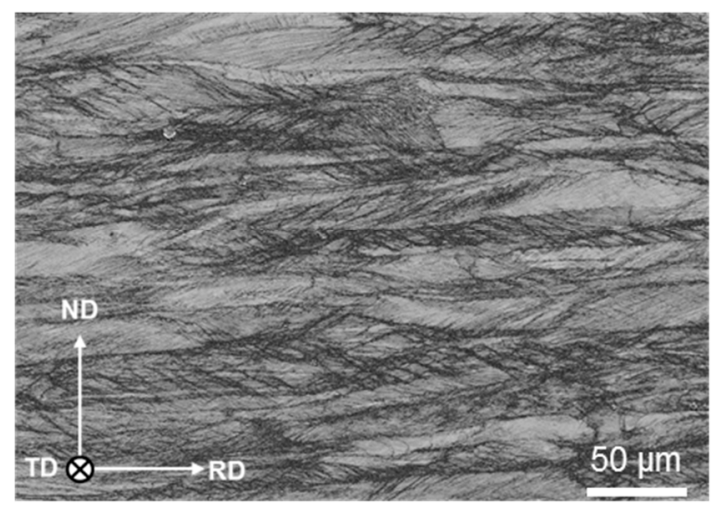

HEA

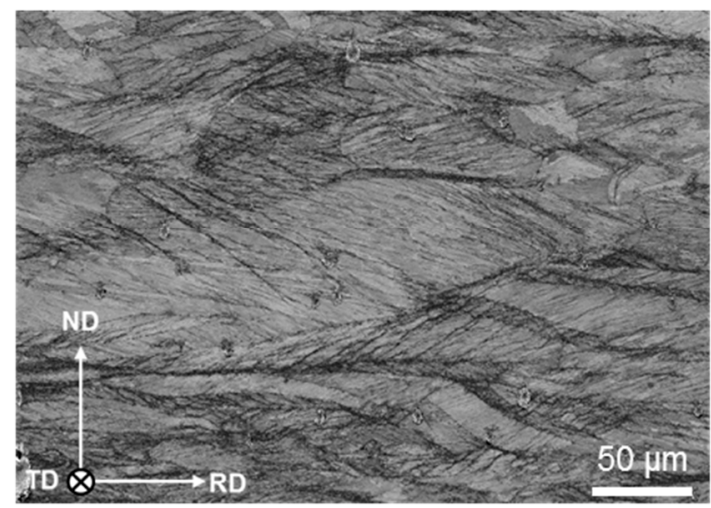

(a)
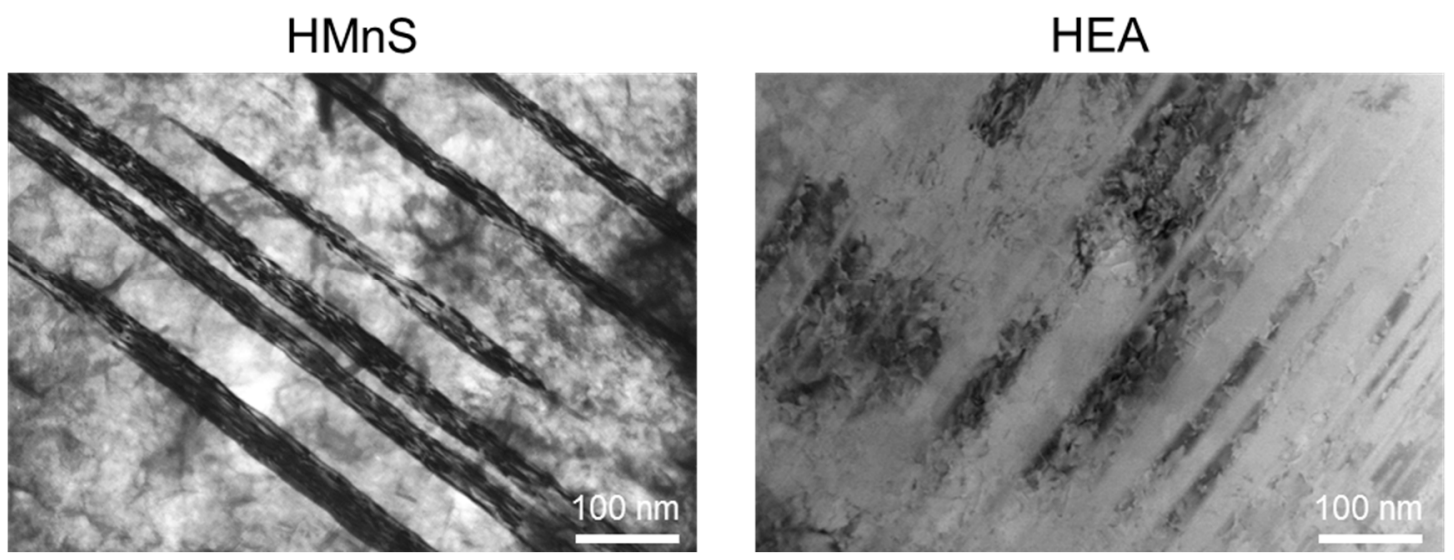

(b)

Figure 2. (a) Electron backscatter diffraction (EBSD) band contrast maps (top) and (b) TEM micrographs (bottom) of the HMnS and HEA after $50 \%$ cold rolling.

\subsection{Behavior during Heat Treatment}

The texture evolution during the heat treatment of the 50\% cold-rolled HMnS and HEA is shown in Figures 3 and 4. Both alloy systems revealed a slight texture strengthening during static recovery, as substantiated by the increased volume fraction of the main texture components and a decreased fraction of randomly oriented grains (Figure 4). It has been shown before that the texture strengthening is caused by a reduced dislocation density due to recovery processes, which results in less scattering of radiation during XRD measurements [23]. During the recovery stage, the twins induced by cold rolling are thermally stable, and will not collapse upon annealing, but they can be consumed by newly formed grains during primary recrystallization (Figure 5). With the onset of recrystallization, the volume fraction of randomly oriented grains increased, whereas the fraction of the main rolling texture components decreased (Figure 4). This trend was further intensified with increasing recrystallized volume fraction. Nevertheless, the main rolling texture components were retained during recrystallization, although with lower intensity. In addition, a weak complete $\alpha$-fiber was formed. 


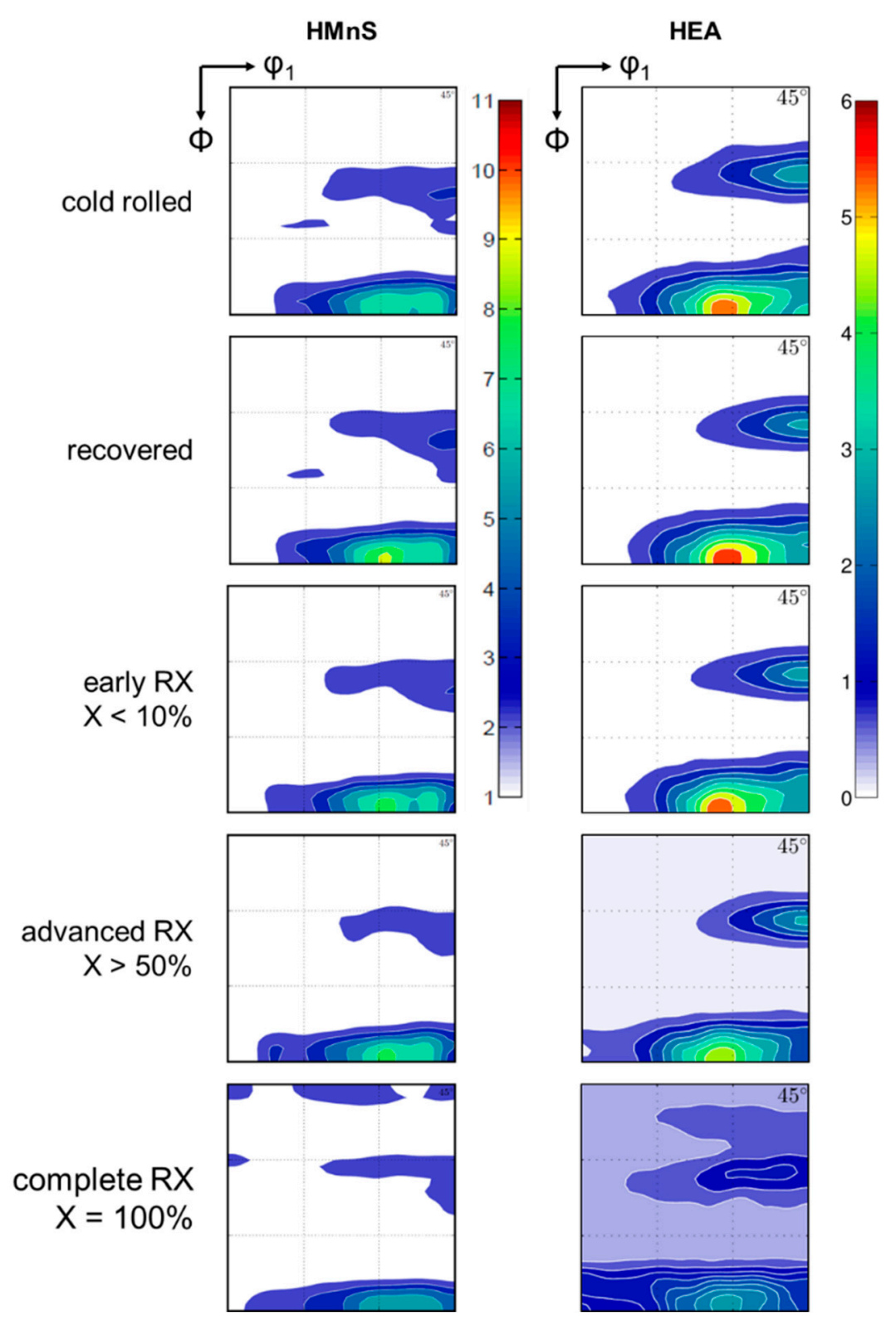

Figure 3. Texture evolution during annealing of the $50 \%$ cold-rolled HMnS and HEA illustrated by $\varphi_{2}$ $=45^{\circ}$ section of the orientation distribution functions $(\mathrm{ODF})$.
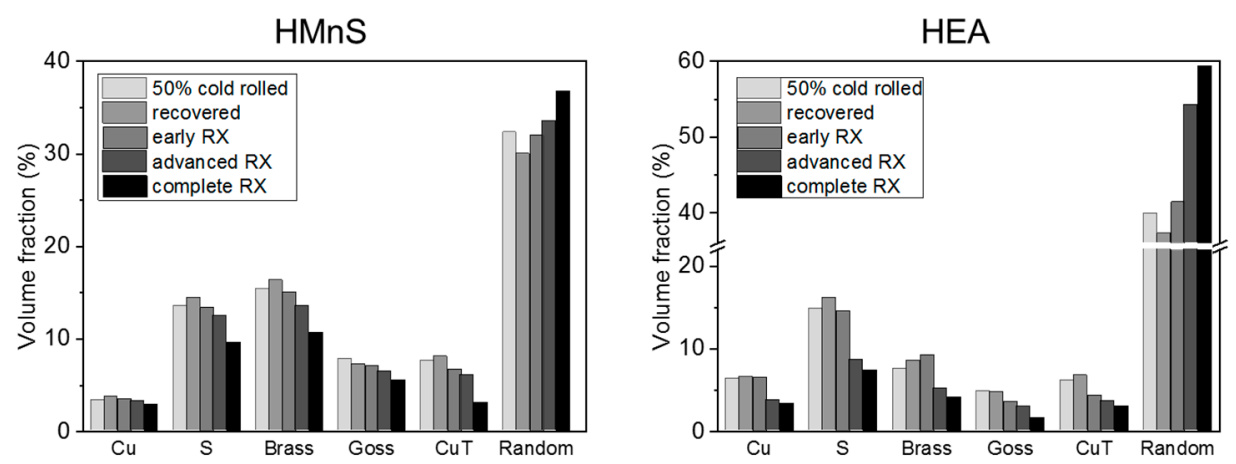

Figure 4. Evolution of the volume fractions of the main texture components during annealing of the $50 \%$ cold-rolled HMnS and HEA. 
HMnS
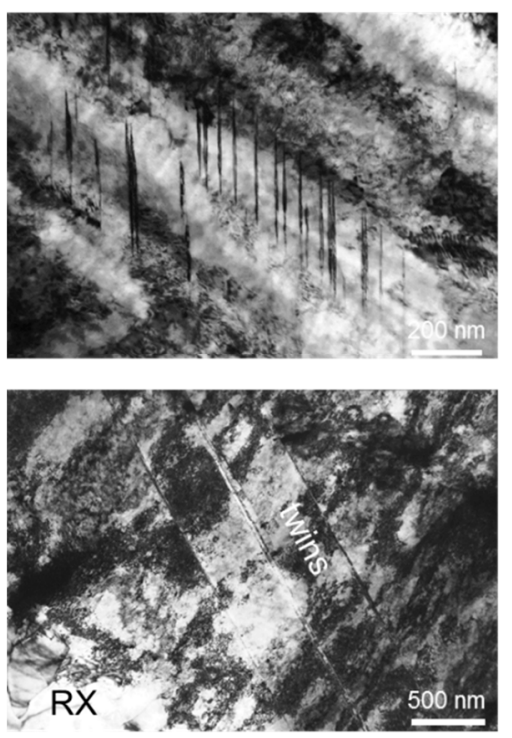

HEA
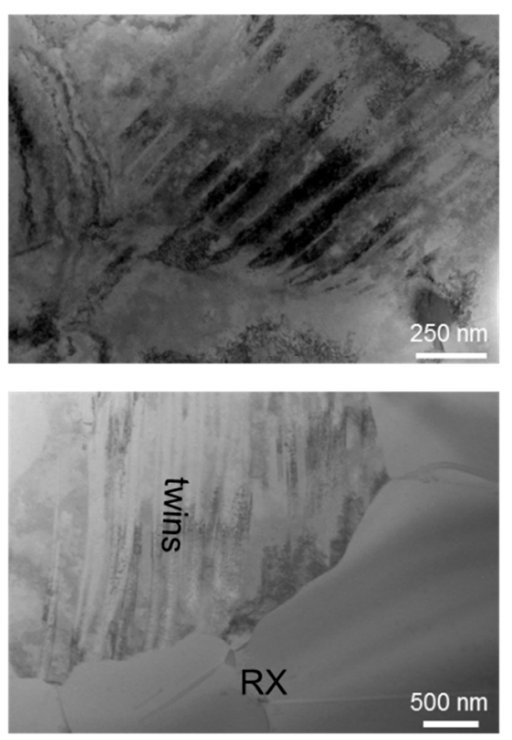

Figure 5. TEM bright-field images of the HMnS and HEA after $50 \%$ cold rolling and subsequent recovery annealing (top) and partial recrystallization (bottom).

In both alloys, the nucleation sites were found to be distributed heterogeneously at grain boundaries and triple junctions (Figure 6). New grains formed and grew primarily by strain-induced grain boundary migration. In this case, the orientations of nuclei were defined by the orientation of subgrains/dislocation cells in the deformed matrix. Additionally, extensive annealing twinning contributed to the formation of new texture components, and thus texture randomization [34]. As has been shown before, first-order twinning within Goss-oriented, Goss/Brass-oriented, and Brass-oriented nuclei resulted in the formation of a complete $\alpha$-fiber due to the development of the A and rotated Goss (RtG) texture components $[8,35,36]$. Therefore, the evolution of the recyrstallization texture of the HMnS and HEA is a result of texture retention due to grain boundary nucleation and texture randomization due to annealing twinning [8,37].
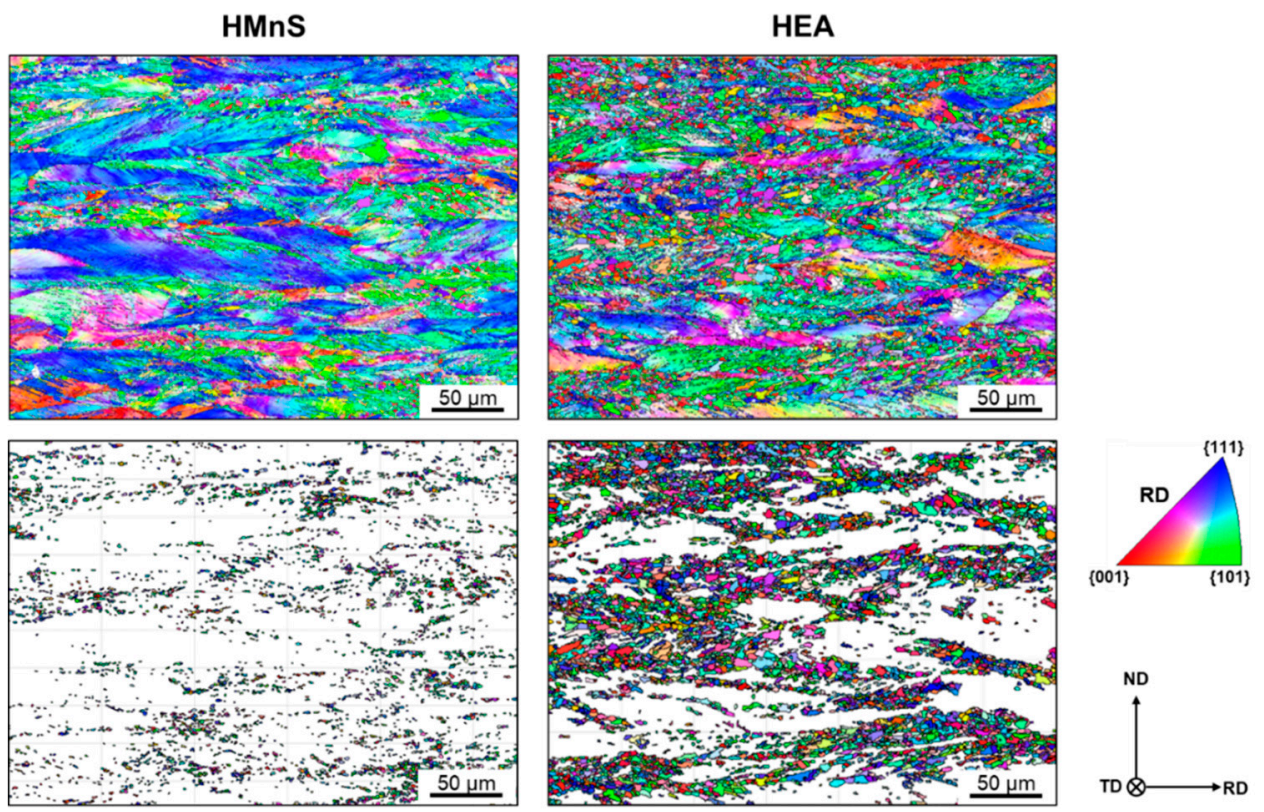

Figure 6. EBSD maps with color-coding according to the inverse pole figure of the HMnS and HEA after $50 \%$ cold rolling and partial recrystallization showing all grains (top row) and only recrystallized grains (bottom row). 


\subsection{Mechanical Properties}

The results of uniaxial tensile tests of the HMnS and HEA after cold rolling and recrystallization are shown in Figure 7. In both cases, the cold-rolled conditions (CR) were characterized by a very high yield and ultimate tensile strength, but a strongly reduced total elongation. During subsequent recovery annealing $(\mathrm{RC})$, the high yield strength was retained due to the thermal stability of deformation twins, whereas the total elongation was enhanced due to dislocations' annihilation [38,39]. After partial recrystallization (PRX) and complete recrystallization (RX), the soft recrystallized grains promoted increased total elongation at the expense of strength. In contrast to the deformed grains subjected to cold rolling, the soft RX grains facilitated regained formability due to the capability of accumulating new dislocations and undergoing deformation twinning [40,41].

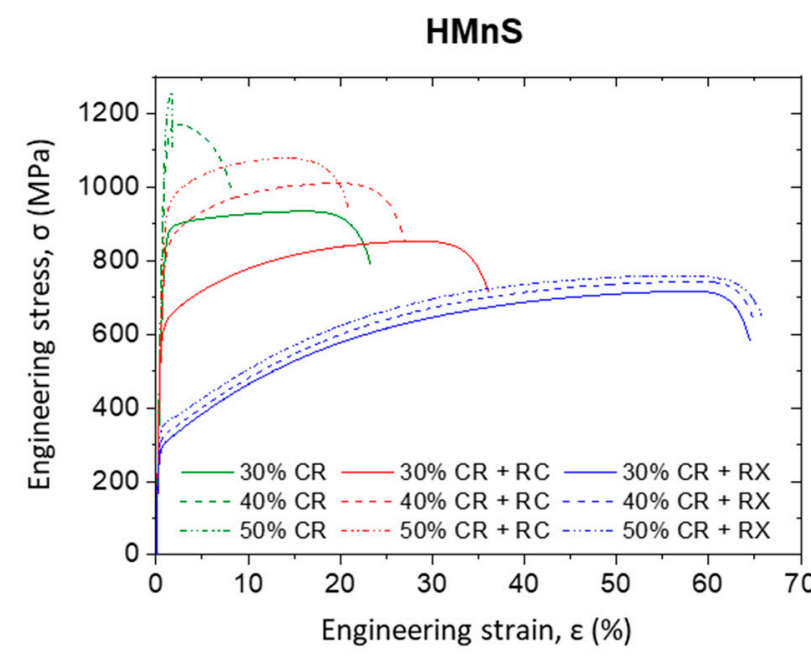

HEA

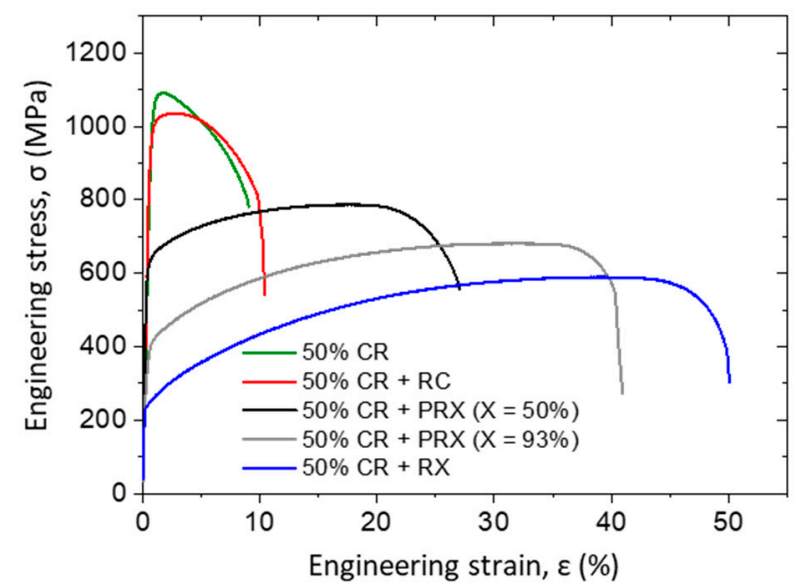

Figure 7. Engineering stress-strain curves of the HMnS and HEA in the states cold rolled (CR), recovered (RC), partially recrystallized (PRX with recrystallized fraction $\mathrm{X}$ ), and recrystallized (RX).

\section{Mechanism-Oriented Alloy Design}

It has been shown and discussed in Sections 3.1-3.3 that the investigated HMnS and HEA behave very similarly. Based on the correlation between microstructure and texture evolution during deformation and heat treatment, it was demonstrated that the influence of the SFE on the material behavior of HMnS also holds true for fcc C-free HEA. The low SFE of both alloys facilitated the activation of twinning during deformation, albeit at different strains, as well as softening by static recovery and recrystallization during annealing. As a consequence, thermomechanical treatment resulted in comparable property profiles of the HMnS and HEA with minor differences due to the 
presence of $C$ in the HMnS, which enabled higher strength and more pronounced twinning. Therefore, it can be asserted that SFE-based, mechanism-oriented alloy design, as has been used for tailoring the properties of HMnS for more than two decades, is a promising methodology to develop new advanced HEAs.

As shown in Figure 8, the activation/suppression of specific deformation mechanisms can be used to tailor the deformation behavior and mechanical properties of HMnS in a wide range. With an SFE $\leq 20 \mathrm{~mJ} / \mathrm{m}^{2}$, the TRIP effect promotes strong work hardening, whereas the TWIP $\left(20 \mathrm{~mJ} / \mathrm{m}^{2} \leq \mathrm{SFE}\right.$ $\leq 50 \mathrm{~mJ} / \mathrm{m}^{2}$ ) and slip-band refinement-induced plasticity (SRIP) (SFE $\geq 50 \mathrm{~mJ} / \mathrm{m}^{2}$ ) effects result in a lower work-hardening potential. Strength and work-hardening capability can be further modified by combining the aforementioned mechanisms with multi-phase (medium-manganese steels (MMnS)) and precipitation ( $\mathrm{k}$-carbides) strengthening (Figure 8). Furthermore, the activation/suppression of specific mechanisms can also be adjusted by precise process design. These approaches include using the higher thermal stability of deformation twins over dislocations during recovery annealing, suppression and activation of twinning during, respectively, warm deformation, e.g., ECAP, and further room temperature deformation or tailoring the work-hardening behavior by using the strong orientation dependence of twinning in anisotropic additively manufactured specimens (Figure 8).
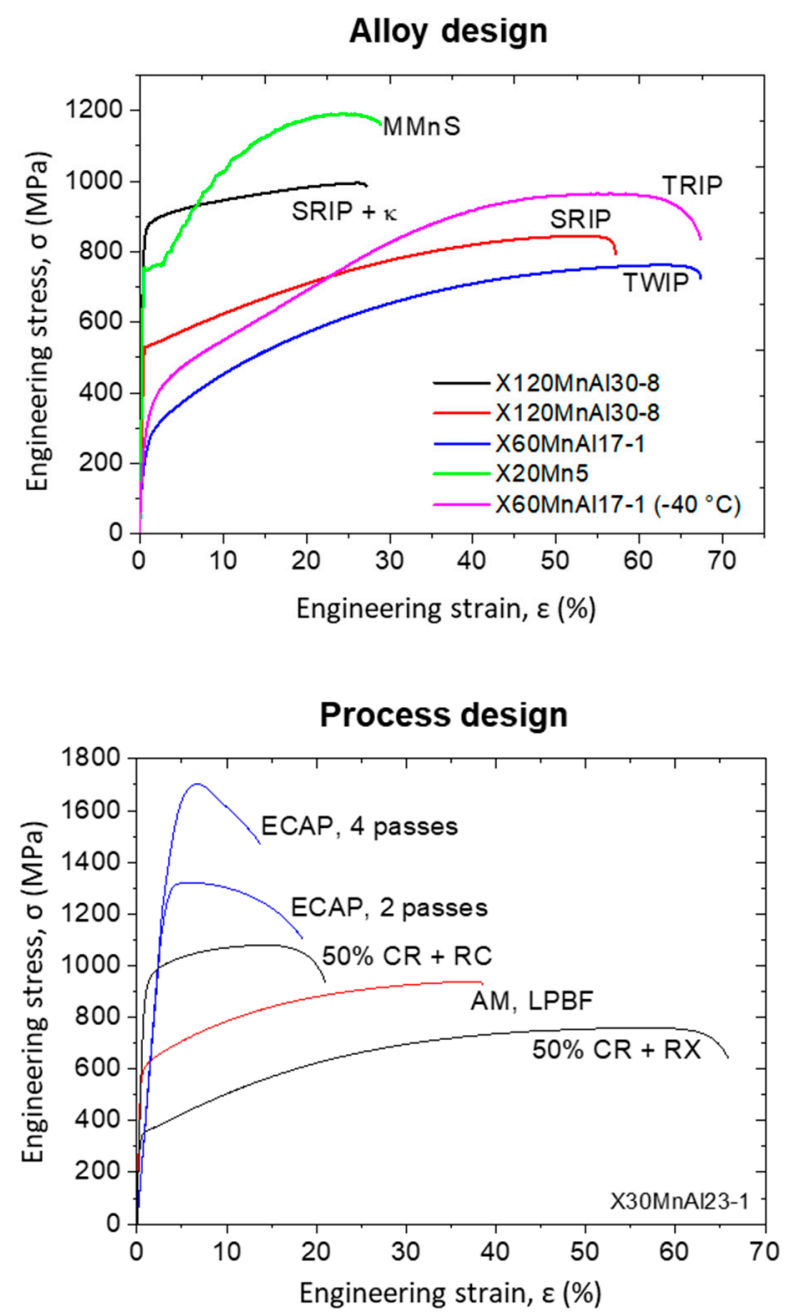

Figure 8. Engineering stress-strain curves of $\mathrm{HMnS}$ with various SFE/activated deformation mechanisms and the X30MnAl23-1 HMnS subjected to different processing techniques. MMnS-medium-manganese steel [42], SRIP—slip-band refinement-induced plasticity [43], TRIP—transformation-induced plasticity, TWIP—twinning-induced plasticity [44], ECAP—equal-channel angular pressing [45], SLM—selective laser melting [46]. 
Indeed, several of the approaches presented in Figure 8 have already been transferred to HEAs, such as TRIP and TWIP effects [17,47], precipitation hardening in compositionally complex alloys (CCAs) [48], recovery annealing [8], severe plastic deformation [49], additive manufacturing [50], etc. However, the further maturity of thermodynamics-based [51,52] and ab initio methods are required to explore the wide composition space of HEAs and CCAs. The mechanism-oriented design will certainly enable unveiling the full potential of these alloys.

\section{Conclusions}

A high-manganese steel and a high-entropy alloy with similar SFE were investigated regarding their microstructure, texture, and mechanical properties after cold rolling and heat treatment. The mechanisms for microstructure modification in both alloys were found to be similar due to the activation of the same physical mechanisms. During plastic deformation at low temperatures, the alloys substantiated initially deformation by dislocation slip and subsequently twinning. However, the onset of twinning in the HEA occurs at higher strains. This effect was attributed to the presence of carbon atoms in solid solution in the steel, whose hardening effect allows reaching the critical stress for twin formation earlier. Consequently, both alloys developed similar textures, but equivalent texture components developed at higher strains in the HEA. Upon annealing, the alloys substantiated the thermal stability of the twins formed during deformation in the recovery range. This effect permits the utilization of recovery annealing treatments in HEA for pronounced ductility and strength. In turn, during recrystallization, a retention of the texture due to grain boundary nucleation and texture randomization as a result of the formation and growth of annealing twins was exhibited. Finally, the mechanical characterization of the alloys evidenced the substantial range of variability of the properties that can be obtained from these alloys.

This suggests that fcc-HEAs can be almost arbitrarily tailored by a combination of the diverse physical mechanisms of microstructure modification that can be triggered in these alloys. The applicability and the potential of mechanisms-oriented alloys design have been already proven by the Collaborative Research Center (SFB) 761 "Steel—ab initio" [6], whose strategy can be used to design new HEAs and CCAs.

Author Contributions: Conceptualization, C.H. and L.A.B.-M.; formal analysis, C.H. and L.A.B.-M.; investigation, C.H. and L.A.B.-M.; visualization, C.H. and L.A.B.-M.; writing-original draft, C.H. and L.A.B.-M.; writing-review \& editing, C.H. and L.A.B.-M.

Funding: This research was funded by the "Deutsche Forschungsgemeinschaft" (DFG) within the Sonderforschungsbereich (Collaborative Research Center) 761 "Steel-ab initio".

Acknowledgments: The authors are thankful for the help of Arndt Ziemons, Marie Luise Köhler, Mehran Afshar, Christian Schnatterer, Johannes Lohmar, and Stefan Senge with carrying out the experiments.

Conflicts of Interest: The authors declare no conflict of interest.

\section{Appendix A}

Table A1. Processing parameters used for the HMnS and HEA in different conditions. CR, RC, PRX, and RX denote cold rolled, recovered, partially recrystallized with recrystallized fraction $X$ and recrystallized, respectively.

\begin{tabular}{ccccc}
\hline Alloy & Condition & $\begin{array}{c}\text { Rolling } \\
\text { Degree (\%) }\end{array}$ & $\begin{array}{c}\text { Annealing } \\
\text { Temperature }\left({ }^{\circ} \mathbf{C}\right)\end{array}$ & $\begin{array}{c}\text { Annealing } \\
\text { Time (h) }\end{array}$ \\
\hline HMnS & CR10 & 10 & - & - \\
HMnS & CR25 & 25 & - & - \\
HMnS & CR50 & 50 & - & - \\
HMnS & CR50 + RC & 50 & 500 & 1 \\
HMnS & CR50 + PRX $(X<10 \%)$ & 50 & 600 & 1 \\
HMnS & CR50 + PRX $(X>50 \%)$ & 50 & 650 & 1 \\
\hline
\end{tabular}


Table A1. Cont.

\begin{tabular}{ccccc}
\hline Alloy & Condition & $\begin{array}{c}\text { Rolling } \\
\text { Degree (\%) }\end{array}$ & $\begin{array}{c}\text { Annealing } \\
\text { Temperature }\left({ }^{\circ} \mathbf{C}\right)\end{array}$ & $\begin{array}{c}\text { Annealing } \\
\text { Time (h) }\end{array}$ \\
\hline HMnS & CR50 + RX & 50 & 700 & 1 \\
HEA & 20.3 & 10 & - & - \\
HEA & CR25 & 25 & - & - \\
HEA & CR50 & 50 & - & - \\
HEA & CR50 + RC & 50 & 550 & 0.5 \\
HEA & CR50 + PRX $(X<10 \%)$ & 50 & 550 & 1 \\
HEA & CR50 + PRX $(X>50 \%)$ & 50 & 550 & 2 \\
HEA & CR50 + RX & 50 & 700 & 8 \\
\hline
\end{tabular}

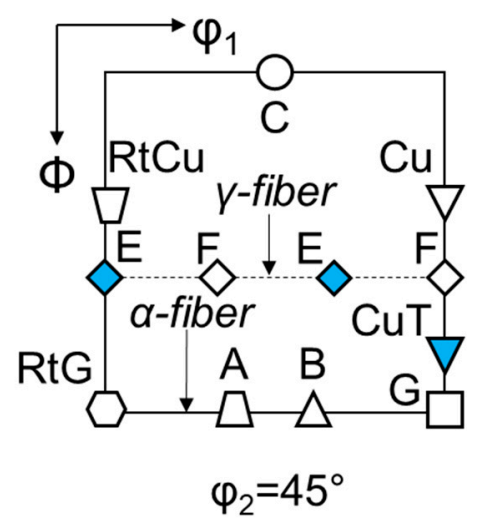

Figure A1. Schematic illustration of the ideal texture components and fibers, ODF section at $\varphi_{2}=45^{\circ}$. The texture components are defined in Table A2.

Table A2. Definition of texture components illustrated in Figure A1.

\begin{tabular}{|c|c|c|c|c|}
\hline Component & Symbol & Miller Indices & Euler Angles $\left(\varphi_{1}, \Phi, \varphi_{2}\right)$ & Fiber \\
\hline Brass (B) & & $\{110\}<112>$ & $(55,90,45)$ & $\alpha, \beta$ \\
\hline Goss (G) & & $\{110\}<100>$ & $(90,90,45)$ & $\alpha, \tau$ \\
\hline Rotated Goss (RtG) & & $\{110\}<110>$ & $(0,90,45)$ & $\alpha$ \\
\hline A & & $\{110\}<111>$ & $(35,90,45)$ & $\alpha$ \\
\hline Cube (C) & & $\{001\}<100>$ & $(45,0,45)$ & / \\
\hline E & & $\{111\}<110>$ & $(0 / 60,55,45)$ & $\gamma$ \\
\hline $\mathrm{F}$ & & $\{111\}<112>$ & $(30 / 90,55,45)$ & $\gamma$ \\
\hline Copper $(\mathrm{Cu})$ & & $\{112\}<111>$ & $(90,35,45)$ & $\beta, \tau$ \\
\hline Copper Twin (CuT) & & $\{552\}<115>$ & $(90,74,45)$ & $\tau$ \\
\hline $\mathrm{S}$ & & $\{123\}<634>$ & $(59,37,63)$ & $\beta$ \\
\hline$\alpha$-fiber & \multirow{3}{*}{\multicolumn{4}{|c|}{$\begin{array}{c}<110>\text { parallel to ND } \\
<110>\text { tilted } 60^{\circ} \text { from ND towards RD } \\
<111>\text { parallel ND }\end{array}$}} \\
\hline$\beta$-fiber & & & & \\
\hline$\gamma$-fiber & & & & \\
\hline
\end{tabular}




\section{References}

1. Bouaziz, O.; Allain, S.; Scott, C.P.; Cugy, P.; Barbier, D. High manganese austenitic twinning induced plasticity steels: A review of the microstructure properties relationships. Curr. Opin. Solid State Mater. Sci. 2011, 15, 141-168. [CrossRef]

2. De Cooman, B.C.; Chen, L.; Kim, H.S.; Estrin, Y.; Kim, S.K.; Voswinckel, H. State-of-the-Science of High Manganese TWIP Steels for Automotive Applications. In Proceedings of the International Conference on Microstructure and Texture in Steels and Other Materials, Jamshedpur, India, 5-7 February 2008; Haldar, A., Suwas, S., Bhattacharjee, D., Eds.; Springer: London, UK, 2008; pp. 165-182.

3. Cantor, B.; Chang, I.T.H.; Knight, P.; Vincent, A.J.B. Microstructural development in equiatomic multicomponent alloys. Mater. Sci. Eng. A 2004, 375, 213-218. [CrossRef]

4. Yeh, J.W.; Chen, S.K.; Lin, S.J.; Gan, J.Y.; Chin, T.S.; Shun, T.T.; Tsau, C.H.; Chang, S.Y. Nanostructured high-entropy alloys with multiple principal elements: Novel alloy design concepts and outcomes. Adv. Eng. Mater. 2004, 6, 299-303. [CrossRef]

5. Murty, B.S.; Yeh, J.W.; Ranganathan, S. High-entropy alloys: Basic concepts. In High Entropy Alloys; Butterworth-Heinemann: Boston, MA, USA, 2014; pp. 13-35.

6. Sonderforschungsbereich 761. Available online: http://abinitio.iehk.rwth-aachen.de/ (accessed on 7 June 2019).

7. Gottstein, G. Physical Foundations of Materials Science; Springer: Berlin/Heidelberg, Germany, 2004.

8. Haase, C.; Barrales-Mora, L.A. Influence of deformation and annealing twinning on the microstructure and texture evolution of face-centered cubic high-entropy alloys. Acta Mater. 2018, 150, 88-103. [CrossRef]

9. Zaddach, A.J.; Niu, C.; Koch, C.C.; Irving, D.L. Mechanical properties and stacking fault energies of $\mathrm{NiFeCrCoMn} \mathrm{high-entropy} \mathrm{alloy.} \mathrm{JOM} \mathrm{2013,} \mathrm{65,} \mathrm{1780-1789.} \mathrm{[CrossRef]}$

10. Huang, S.; Li, W.; Lu, S.; Tian, F.; Shen, J.; Holmström, E.; Vitos, L. Temperature dependent stacking fault energy of FeCrCoNiMn high entropy alloy. Scripta Mater. 2015, 108, 44-47. [CrossRef]

11. Otto, F.; Dlouhý, A.; Somsen, C.; Bei, H.; Eggeler, G.; George, E.P. The influences of temperature and microstructure on the tensile properties of a CoCrFeMnNi high-entropy alloy. Acta Mater. 2013, 61, 5743-5755. [CrossRef]

12. Ikeda, Y.; Grabowski, B.; Körmann, F. Ab initio phase stabilities and mechanical properties of multicomponent alloys: A comprehensive review for high entropy alloys and compositionally complex alloys. Mater. Charact. 2019, 147, 464-511. [CrossRef]

13. Zhao, S.; Stocks, G.M.; Zhang, Y. Stacking fault energies of face-centered cubic concentrated solid solution alloys. Acta Mater. 2017, 134, 334-345. [CrossRef]

14. Ikeda, Y.; Körmann, F.; Tanaka, I.; Neugebauer, J. Impact of chemical fluctuations on stacking fault energies of $\mathrm{CrCoNi}$ and $\mathrm{CrMnFeCoNi}$ high entropy alloys from first principles. Entropy 2018, 20, 655. [CrossRef]

15. Beyramali Kivy, M.; Asle Zaeem, M. Generalized stacking fault energies, ductilities, and twinnabilities of CoCrFeNi-based face-centered cubic high entropy alloys. Scripta Mater. 2017, 139, 83-86. [CrossRef]

16. Liu, S.F.; Wu, Y.; Wang, H.T.; He, J.Y.; Liu, J.B.; Chen, C.X.; Liu, X.J.; Wang, H.; Lu, Z.P. Stacking fault energy of face-centered-cubic high entropy alloys. Intermetallics 2018, 93, 269-273. [CrossRef]

17. Li, Z.; Pradeep, K.G.; Deng, Y.; Raabe, D.; Tasan, C.C. Metastable high-entropy dual-phase alloys overcome the strength-ductility trade-off. Nature 2016, 534, 227-230. [CrossRef] [PubMed]

18. Li, Z.; Tasan, C.C.; Springer, H.; Gault, B.; Raabe, D. Interstitial atoms enable joint twinning and transformation induced plasticity in strong and ductile high-entropy alloys. Sci. Rep. 2017, 7, 40704. [CrossRef] [PubMed]

19. Saeed-Akbari, A.; Imlau, J.; Prahl, U.; Bleck, W. Derivation and variation in composition-dependent stacking fault energy maps based on subregular solution model in high-manganese steels. Metall. Mater. Trans. A 2009, 40, 3076-3090. [CrossRef]

20. Hielscher, R.; Schaeben, H. A novel pole figure inversion method: Specification of the MTEX algorithm. J. Appl. Crystallogr. 2008, 41, 1024-1037. [CrossRef]

21. Bachmann, F.; Hielscher, R.; Schaeben, H. Texture analysis with MTEX-Free and open source software toolbox. Soild State Phenom 2010, 160, 63-68. [CrossRef]

22. Bachmann, F.; Hielscher, R.; Schaeben, H. Grain detection from $2 \mathrm{~d}$ and $3 \mathrm{~d}$ EBSD data-Specification of the MTEX algorithm. Ultramicroscopy 2011, 111, 1720-1733. [CrossRef] 
23. Haase, C.; Barrales-Mora, L.A.; Molodov, D.A.; Gottstein, G. Tailoring the mechanical properties of a twinning-induced plasticity steel by retention of deformation twins during heat treatment. Metall. Mater. Trans. A 2013, 44, 4445-4449. [CrossRef]

24. Haase, C.; Chowdhury, S.G.; Barrales-Mora, L.A.; Molodov, D.A.; Gottstein, G. On the relation of microstructure and texture evolution in an austenitic Fe-28Mn-0.28C TWIP steel during cold rolling. Metall. Mater. Trans. A 2013, 44, 911-922. [CrossRef]

25. Sathiaraj, G.D.; Ahmed, M.Z.; Bhattacharjee, P.P. Microstructure and texture of heavily cold-rolled and annealed fcc equiatomic medium to high entropy alloys. J. Alloys Compd. 2016, 664, 109-119. [CrossRef]

26. Sevsek, S.; Brasche, F.; Haase, C.; Bleck, W. Combined deformation twinning and short-range ordering causes serrated flow in high-manganese steels. Mater. Sci. Eng. A 2019, 746, 434-442. [CrossRef]

27. Hirsch, J.; Lücke, K.; Hatherly, M. Mechanism of deformation and development of rolling textures in polycrystalline F.C.C. metals-III. The influence of slip inhomogeneities and twinning. Acta Metall. 1988, 36, 2905-2927. [CrossRef]

28. Vercammen, S.; Blanpain, B.; De Cooman, B.C.; Wollants, P. Cold rolling behaviour of an austenitic Fe-30Mn-3Al-3Si TWIP-steel: The importance of deformation twinning. Acta Mater. 2004, 52, 2005-2012. [CrossRef]

29. Kusakin, P.; Belyakov, A.; Haase, C.; Kaibyshev, R.; Molodov, D.A. Microstructure evolution and strengthening mechanisms of Fe-23Mn-0.3C-1.5Al TWIP steel during cold rolling. Mater. Sci. Eng. A 2014, 617, 52-60. [CrossRef]

30. Saleh, A.A.; Haase, C.; Pereloma, E.V.; Molodov, D.A.; Gazder, A.A. On the evolution and modelling of brass-type texture in cold-rolled twinning-induced plasticity steel. Acta Mater. 2014, 70, 259-271. [CrossRef]

31. Stepanov, N.; Tikhonovsky, M.; Yurchenko, N.; Zyabkin, D.; Klimova, M.; Zherebtsov, S.; Efimov, A.; Salishchev, G. Effect of cryo-deformation on structure and properties of CoCrFeNiMn high-entropy alloy. Intermetallics 2015, 59, 8-17. [CrossRef]

32. Klimova, M.; Stepanov, N.; Shaysultanov, D.; Chernichenko, R.; Yurchenko, N.; Sanin, V.; Zherebtsov, S. Microstructure and mechanical properties evolution of the $\mathrm{Al}, \mathrm{C}$-containing $\mathrm{CoCrFeNiMn-type} \mathrm{high-entropy}$ alloy during cold rolling. Materials 2018, 11, 53. [CrossRef]

33. Klimova, M.; Zherebtsov, S.; Stepanov, N.; Salishchev, G.; Haase, C.; Molodov, D.A. Microstructure and texture evolution of a high manganese TWIP steel during cryo-rolling. Mater. Charact. 2017, 132, 20-30. [CrossRef]

34. Gottstein, G. Annealing texture development by multiple twinning in F.C.C. crystals. Acta Metall. 1984, 32, 1117-1138. [CrossRef]

35. Haase, C.; Barrales-Mora, L.A.; Molodov, D.A.; Gottstein, G. Texture evolution of a cold-rolled Fe-28Mn-0.28C TWIP steel during recrystallization. Mater. Sci. Forum 2013, 753, 213-216. [CrossRef]

36. Haase, C.; Kühbach, M.; Barrales Mora, L.A.; Wong, S.L.; Roters, F.; Molodov, D.A.; Gottstein, G. Recrystallization behavior of a high-manganese steel: Experiments and simulations. Acta Mater. 2015, 100, 155-168. [CrossRef]

37. Haase, C.; Ingendahl, T.; Güvenç, O.; Bambach, M.; Bleck, W.; Molodov, D.A.; Barrales-Mora, L.A. On the applicability of recovery-annealed twinning-induced plasticity steels: Potential and limitations. Mater. Sci. Eng. A 2016, 649, 74-84. [CrossRef]

38. Haase, C.; Barrales-Mora, L.A.; Roters, F.; Molodov, D.A.; Gottstein, G. Applying the texture analysis for optimizing thermomechanical treatment of high manganese twinning-induced plasticity steel. Acta Mater. 2014, 80, 327-340. [CrossRef]

39. Berrenberg, F.; Haase, C.; Barrales-Mora, L.A.; Molodov, D.A. Enhancement of the strength-ductility combination of twinning-induced/transformation-induced plasticity steels by reversion annealing. Mater. Sci. Eng. A 2017, 681, 56-64. [CrossRef]

40. Yanushkevich, Z.; Belyakov, A.; Haase, C.; Molodov, D.A.; Kaibyshev, R. Structural/textural changes and strengthening of an advanced high-Mn steel subjected to cold rolling. Mater. Sci. Eng. A 2016, 651, 763-773. [CrossRef]

41. Yanushkevich, Z.; Belyakov, A.; Kaibyshev, R.; Haase, C.; Molodov, D.A. Effect of cold rolling on recrystallization and tensile behavior of a high-Mn steel. Mater. Charact. 2016, 112, 180-187. [CrossRef]

42. Sevsek, S.; Haase, C.; Bleck, W. Strain-rate-dependent deformation behavior and mechanical properties of a multi-phase medium-manganese steel. Metals 2019, 9, 344. [CrossRef] 
43. Haase, C.; Zehnder, C.; Ingendahl, T.; Bikar, A.; Tang, F.; Hallstedt, B.; Hu, W.; Bleck, W.; Molodov, D.A. On the deformation behavior of $\mathrm{K}$-carbide-free and $\mathrm{k}$-carbide-containing high-Mn light-weight steel. Acta Mater. 2017, 122, 332-343. [CrossRef]

44. Haase, C.; Barrales-Mora, L.A.; Molodov, D.A.; Gottstein, G. Application of texture analysis for optimizing thermo-mechanical treatment of a high Mn TWIP steel. Adv. Mater. Res. 2014, 922, 213-218. [CrossRef]

45. Haase, C.; Kremer, O.; Hu, W.; Ingendahl, T.; Lapovok, R.; Molodov, D.A. Equal-channel angular pressing and annealing of a twinning-induced plasticity steel: Microstructure, texture, and mechanical properties. Acta Mater. 2016, 107, 239-253. [CrossRef]

46. Kies, F.; Köhnen, P.; Wilms, M.B.; Brasche, F.; Pradeep, K.G.; Schwedt, A.; Richter, S.; Weisheit, A.; Schleifenbaum, J.H.; Haase, C. Design of high-manganese steels for additive manufacturing applications with energy-absorption functionality. Mater. Des. 2018, 160, 1250-1264. [CrossRef]

47. Deng, Y.; Tasan, C.C.; Pradeep, K.G.; Springer, H.; Kostka, A.; Raabe, D. Design of a twinning-induced plasticity high entropy alloy. Acta Mater. 2015, 94, 124-133. [CrossRef]

48. He, J.Y.; Wang, H.; Huang, H.L.; Xu, X.D.; Chen, M.W.; Wu, Y.; Liu, X.J.; Nieh, T.G.; An, K.; Lu, Z.P. A precipitation-hardened high-entropy alloy with outstanding tensile properties. Acta Mater. 2016, 102, 187-196. [CrossRef]

49. Schuh, B.; Mendez-Martin, F.; Völker, B.; George, E.P.; Clemens, H.; Pippan, R.; Hohenwarter, A. Mechanical properties, microstructure and thermal stability of a nanocrystalline CoCrFeMnNi high-entropy alloy after severe plastic deformation. Acta Mater. 2015, 96, 258-268. [CrossRef]

50. Ewald, S.; Kies, F.; Hermsen, S.; Voshage, M.; Haase, C.; Schleifenbaum, J.H. Rapid alloy development of extremely high-alloyed metals using powder blends in laser powder bed fusion. Materials 2019, 12, 1706. [CrossRef] [PubMed]

51. Haase, C.; Tang, F.; Wilms, M.B.; Weisheit, A.; Hallstedt, B. Combining thermodynamic modeling and 3D printing of elemental powder blends for high-throughput investigation of high-entropy alloys-Towards rapid alloy screening and design. Mater. Sci. Eng. A 2017, 688, 180-189. [CrossRef]

52. Miracle, D.B.; Senkov, O.N. A critical review of high entropy alloys and related concepts. Acta Mater. 2017, 122, 448-511. [CrossRef] 